\title{
Reverse logistics: a route that only makes sense when adopting a systemic vision
}

\author{
T. R. T. Campos ${ }^{1}$, M. V. A. Fonseca ${ }^{1} \&$ R. M. N. Morais ${ }^{2}$ \\ ${ }^{1}$ Alberto Luiz Coimbra Institute for Graduate Studies and Research in \\ Engineering, Federal University of Rio de Janeiro, Brazil \\ ${ }^{2}$ National Institute of Metrology, Quality and Technology (Inmetro), \\ Brazil
}

\begin{abstract}
The Solid Waste National Policy (SWNP) established by Law No. 12.305/2010 and regulated by Federal Decree No. 7404/2010 indicates advances in solid waste management in Brazil. The main one is the implementation of shared responsibility for the life cycle of products, operationalized through the Reverse Logistics system. This system seeks the restitution of solid waste to the business sector for reusing in the production chain or for environmentally appropriate disposal. The challenge and successful implementation of the SWNP requires the government's strategic vision and a change in the behaviour of the Brazilian population. This process needs to be built through social debate and engagement of all stakeholders, from the social and economic inclusion of waste pickers in the recycling chain to the real commitment of entrepreneurs, transforming degrading jobs in entrepreneurship, combined with innovation. Despite the fact that the SWNP and other regulatory instruments generically indicate a stimulus to the incorporation of non-virgin raw materials in the production process of Electrical and Electronic Equipment (EEE), no concrete step in this direction has been found yet. The complex nature of the productive chain of electrical and electronic products gives an indication of the interlinked network of inter-relationships of the industrial system involved in it, once it depends on the integration of several industries. In this context, it is important to structure a management model for the reuse of industrial waste, based on the creation of a network - 5Rs Network - that allows to Reduce, Redesign, Recycle, Reuse and Repurpose the waste generated throughout the production cycle of the EEE in the country. This paper reveals which industrial sectors are related to the EEE
\end{abstract}


productive chain, focusing on why only with a systemic and holistic view -5 Rs Network - will the Reverse Logistics become effective.

Keywords: industrial waste, reverse logistics, waste electrical and electronic equipment, industrial symbiosis, network.

\section{Introduction}

In manufacturing operations, considerable attention has been given to the minimization of the environmental impacts on process development and design due to the demands of the increasing costs of compliance and environmental regulations that have emerged in recent decades. The focus on the productive chain management abandons, therefore, the perspective of the specific cost approach and adopts a more holistic view of sustainable development [1].

Fonseca [2] defines the productive chain as "a network of inter-relationships between several actors of an industrial system that allows the identification of the flow of goods and services across sectors that are directly committed, from the sources of raw materials to the final consumption of the product".

The importance of balancing the social, environmental, technological and economic objectives on the sustainable development of industries has aroused greater concern in the sustainable design and planning of supply chains in recent years. The combination of environmental management and supply chain management, within a simple structure, led to the emergence of a new discipline called "Green" Supply Chain Management, which includes sustainable design and sustainable operating practices in the productive chain [3-5]).

In this context, certain fundamental aspects are commonly considered: process wastes; efficient use of energy sources; greenhouse gases emission; efficient use of capacity and resources (eco-efficiency); and legal and environmental factors. In fact, the regulations and growing consumer pressure increase the need for integrating environmentally sound choices with the research and practice of productive chain management [1].

In Brazil, with the implementation of the Solid Waste National Policy (SWNP) [6], these questions become relevant, especially with regard to the obligation of shared responsibility for the lifecycle of products, exploited by the Reverse Logistics system.

In this paper, we will focus on the waste originated from industrial processes involved in the electrical and electronic industry sector, addressing the concept of eco-efficiency, supported by the principles and objectives of the SWNP.

\section{Green management of the productive chain}

Sustainability requires the integration of processes that extend beyond the fundamental aspects of the supply chain management, such as product design, manufacture of by-products, by-products produced during the product's use, product lifespan, end of its useful life, and recovery processes at the end of its 
useful life. In order to design and optimize supply chains, with respect to environmental principles, it is necessary to ensure energy conservation and waste management throughout the stages of the supply chain [1].

\subsection{Challenges}

The projects of environmentally sound industrial processes should be developed with a systemic view, adopting a strategy that considers environmental issues as key objectives in order to achieve better performance, both economic and environmental.

The design of the environmentally sound product involves the integration of an environmental vision from its conception to delivery and final disposal of the product [1]. Considering these issues in the early stages of the development process, however, increases the complexity of designing tasks, which is further complicated by the need to consider different conflicting criteria as well as the various sources of uncertainty, demand and prices $[1,7]$.

A sustainable decision making is often made, considering only inventory management, production planning, product recovery, etc. Nikolopoulou and Ieraperitou [1] suggest that integrated methodologies that combine two or more of these approaches are examined by both the academic community and the industry in order to have a more realistic analysis of the systems under investigation.

This holistic approach allows for the definition of responsibilities in the management of solid wastes to be structured, identifying innovative business opportunities.

\section{The SWNP and the shared environmental responsibility}

The SWNP established by Law no. 12.305/2010 [6], regulated by Federal Decree no. 7.404/2010 [8], indicates significant improvements in the management of solid wastes in Brazil. The main one is the shared responsibility for the lifecycle of products, operationalized through the Reverse Logistics system. This instrument is identified by some environmentalists as one of the main resistance points of the long course of the bill in Congress, which took 20 years to be approved.

The challenge and successful implementation of the SWNP requires the government's strategic vision and a change in the behaviour of the Brazilian population. This process needs to be built by means of social debate and engagement of all stakeholders, from the expansion of opportunities for social and economic inclusion of waste pickers in the recycling chain, to the real commitment of entrepreneurs, transforming degrading jobs in entrepreneurship, allied to innovation, besides the opportunity of promoting and establishing the new concept of green economy.

Reverse Logistics is defined in the law as the "economic and social development instrument characterized by a set of actions, procedures and means 
to enable the collection and recovery of the solid waste to the business sector, for reuse, in its cycle or other production cycles, or other environmentally appropriate disposal". Therefore, Reverse Logistics is also seen as a way of ensuring the return of the products post-consumption or post-sale. This is because the concern of this system is to make any material, which cannot be reused, return to its productive cycle, or to another industry, as input, protecting the nature resources and favouring an environmentally correct disposal.

It is worth noting the existence of other regulations prior to the SWNP that already dealt with the Reverse Logistics: tires, pesticide containers, used or contaminated lubricating oil, and batteries. The law (Art. 33) broadens the scope of the obligation to structure and implement Reverse Logistics systems for other productive chains, such as fluorescent lamps, sodium and mercury vapour and mixed lighting lamps and electrical and electronic products and their components.

The Decree no. 7404 [8] created the Interministerial Committee of the SWNP and the Steering Committee for the Implementation of Reverse Logistics systems (CORI), both with the intention to support the structuring and implementation of the law by coordinating bodies, governmental entities and civil society.

The Interministerial Committee created five working groups (WG) to enable compliance with the determinations and goals provided by the law: WG01 - Implementation and accompaniment of Solid Waste Plans and creation of the SINIR - National System for Information on the Management of Solid Waste; WG02 - Energy Recovery from Urban Solid Waste; WG03 - Finance and credit lines, tax exemption for recyclable and reusable products; WG04 - Hazardous Waste - Management Plan for Hazardous Waste and Decontamination of Orphan Areas and WG05 - Environmental Education.

The Steering Committee has the following responsibilities: establish the strategic direction of the implementation of Reverse Logistics systems; define the methodological guidelines to evaluate the social and economic impacts of the Reverse Logistics systems; promote studies and propose tax exemption measures for supply chains subject to Reverse Logistics. In addition, the $5^{\text {th }}$ article of the Decree establishes that the responsibility for the effectiveness of the SWNP lies upon all members of the supply chain (manufacturers, importers, distributors, traders, consumers and holders of cleaning services and solid waste management) that provide or help in the generation of waste. Those responsible are involved since the initial links of this chain - activities of extraction and obtainment of raw materials - ,passing, in the case of industrial supply chains, through the steps of processing or manufacturing, until the final links of distribution and consumption of finished products.

The decree establishes in Title $\mathrm{V}$ - the participation of waste pickers. According to the $40^{\text {th }}$ article "the system of selective collection of solid waste and the Reverse Logistics prioritize the participation of cooperatives or other forms of association of waste pickers consisting of low-income individuals".

It is important to mention that the decree gives special attention to Reverse Logistics and defines three different tools that could be used for its implementation: regulations, sectoral agreements and term sheet. By allowing 
large social participation, the sectoral agreements have been chosen by the Steering Committee, as the preferred instruments for the implementation of Reverse Logistics.

In order to build the Reverse Logistics system, Thematic Working Groups (TWG) were created with the participation and involvement of different stakeholders to discuss with the government the modelling proposals for Reverse Logistics' five priority supply chains: packaging of lubricating oils; fluorescent lamps, sodium and mercury vapour and mixed lighting lamps, electrical and electronic products and their residues, general packaging and disposal of medicines.

These groups were intended to establish the modelling proposals of Reverse Logistics and the subsidies for the Request for Proposals of Sectoral Agreements, as well as collecting information for studies of technical and economic viability in order to support the Steering Committee in making decisions relevant to the topic. The broad debate with the participation of relevant stakeholders was important to consolidate a negotiation over the final text for the sectoral agreement. A sectoral agreement is defined in the SWNP as "a contractual act, signed between the government and manufacturers, importers, distributors or dealers, with a view to implement shared responsibility for the lifecycle of the product".

Recently the SWNP was the theme of the 4th National Conference on the Environment organized by the Ministry of Environment, aiming to promote a broad debate to contribute to the implementation of the policy with a focus on: sustainable production and consumption, reducing environmental impacts, generation of work, employment and income, and environmental education. This process mobilized more than 200,000 people in $65 \%$ of Brazilian municipalities, which discussed and approved different proposals that were analysed and voted upon at the National Conference. There were 643 municipal and 179 regional conferences to reach the national stage [9].

\subsection{Electrical and electronic waste}

The TWG concluded their work in November 2013 and, according to the SINIR, the ten proposals concerning the implementation of the Reverse Logistics of electrical and electronic products and their residues have been considered by the Ministry of Environment (MMA) and are under discussion with the proponents [10].

The technological advances and rapid incursions of electrical and electronic products require increasingly complex studies of these markets, in particular of their supply chains, especially the management of their waste.

The Basel Convention has set the as theme of its high-level segment at the eighth Conference of the Parties (COP-8) in 2006, creating innovative solutions through the Basel Convention for the environmentally sound management of electrical and electronic wastes. The choice of the theme reflected the worldwide concern over the large waste flow of electrical and electronic equipment and the increasing export of this equipment to developing countries, coupled with the vulnerability of these countries to ensure an environmentally appropriate 
management of such wastes, and thereby increasing the risk associated with the uncontrolled import of these products.

The Brazilian market for electrical and electronic equipment has been growing strongly in recent years. According to the Brazilian Association of Electrical and Electronics Industry [11], the exports are expected to grow 5\%, to U\$8.1 billion, while imports will increase 8\%, reaching U\$43.6 billion. Therefore, the trade deficit in the sector, in 2013, should be $9 \%$ higher than in 2012, totaling U\$35.5 billion (Table 1).

Given that the provisions of the SWNP are being introduced gradually, by the issuance of license regulations by the federal government and the compliance of state and municipal governments, the market for treatment of electrical and electronic equipment waste (EEEW) tends to expand.

It is not possible to carry out a sectoral planning without taking into account the ramifications along the production chain. Therefore, a detailed analysis of the flow of materials or study on the generation of waste in the entire production chain of Electrical and Electronic Equipment (EEE) is critical to support the part of the legislation that addresses the EEEW and the development of new policies.

Table 1: Projections of key indicators of the sector in Brazil.

\begin{tabular}{l|ccc}
\hline & 2012 & 2013 & $2013 \times 2012$ \\
\hline Sales revenue (US\$ million) & 73,931 & 76,491 & $3 \%$ \\
Exports (US\$ million) & 7,719 & 8,100 & $5 \%$ \\
Imports (US\$ million) & 40,222 & 43,600 & $8 \%$ \\
$\mathrm{~N}^{\circ}$ of employees (1000) & 183 & 187 & $2 \%$ \\
\hline
\end{tabular}

Source: ABINEE [11].

One conclusion of the study conducted by Araújo et al. [12], for example, was to identify the need for further research in modeling the generation of EEEW, in order to collect data on the production and collection of EEEW flow. These data would be used to support stakeholders to establish an efficient policy of EEEW in the country, which, however, will depend on a number of critical factors which include: creation of a specific legislation on EEEW, with regulations that are suitable for the regional market with different conditions; establishment of effective and safe controls; structuring a flow of Reverse Logistics, for each type of product that are competitive and at the same time, environmentally and technologically well-structured; and promotion of reuse, renovation and recycling markets.

\section{Eco-efficiency and eco-industrial parks}

In the current scenario of the 21 Environment - contemporary context, characterized by the acceleration of technological, market and values change [13] - the role of technology is to provide solutions, revolutionizing the current organization paradigm of production and consumption. This is a discussion that has encouraged the academia to diligently investigate possible ways to overcome, especially, the scarcity of natural resources and reduction of 
environmental impacts. One of the alternatives found is the creation of a production-consumption system with organization and functioning that are similar to the mechanisms of food webs of living organisms. Comparing industrial processes and the processes of nature, it is noticed that the main difference lies in the fact that, in these last, the total balance of waste is zero. In the cyclical characteristic of nature, waste is food.

It is in this context that the concept of industrial ecology or industrial symbiosis, introduced by Frosch and Gallopoulos [14], emerges. The authors propose the development of industrial symbiosis (IS), in which the Organizations, Industries and Businesses (OIB) should seek to optimize their activities through the reuse of energy and materials throughout the various stages of production and consumption. It is a model based on a concentrated group of industries with the objective to eliminate wastage and reuse all natural resources, free of pollution and toxic residues, different from the traditional industry.

The eco-efficiency (sustainable production of goods and services that are useful to society, aggregating value through the pursuit of the lower consumption of natural resources and minimization/non-generation of environmental impacts - World Business Council for Sustainable Development (WBCSD) [15]) of an OIB is evaluated by its ability to reduce, reuse and recycle its products, thus minimizing the impacts on the environment. To the 3Rs of eco-efficiency, the need to redesign and repurpose are added as innovative ways of developing products and services from industrial waste [16], which are perfectly aligned with some of the basic principles of the SWNP - sustainable development, ecoefficiency and recognition of reusable and recyclable solid waste as an economic and social value as well, generating employment and income and promoting citizenship. Yet, one of its goals, which are to encourage the adoption of sustainable patterns of production and consumption of goods and services, is also added.

Chertow [17] defined the industrial symbiosis as "engaging traditionally separate industries in a collective approach to competitive advantage involving physical exchange of materials, energy, water, and by-products. The keys to industrial symbiosis are collaboration and the synergistic possibilities offered by geographic proximity".

The motivations for industrial symbiosis are, for example, conventionally commercial - the sharing of resources can reduce costs and/or increase revenues. On another level, the industrial symbiosis can increase the security of resources in the long run, increasing the availability of essential resources such as water, energy or certain raw materials by means of contracts. In some cases, companies persist in the symbiosis as a response to the pressure of regulatory instruments, which demand industrial operators to increase the efficiency in the use of resources, reduce emissions, and/or eliminate wastage. The benefits occur in clusters included in a single sector, such as the petrochemical, pharmaceutical, as well as the "multi-industries", such as the Kalundborg's, in Denmark [18].

Identifying and promoting emerging industrial ecosystems offers the promise of many benefits, particularly environmental. It is essential, however, to lead public and private stakeholders through the possibilities of sharing resources in 
geographically related industrial areas, of diversified industrial sectors, by selecting projects with demonstrable nuclei of self-organization that can emerge as more fully viable industrial ecosystems. And the interrelationship of various types of industries involved in the production chain of the electrical and electronics sector represents an excellent opportunity for market creation in the context of products and services in the environmental area, particularly with regard to industrial waste.

\section{Sustainable Reverse Logistics}

Logistics activities involve the material flow forward, through the supply chain, while the Reverse Logistics addresses the return flows from the user and includes reprocessing it to a usable product [19].

By-products and residues are potentially valuable inputs in several industrial processes. The markets are being developed to capitalize on waste, acknowledging the value of the use and reuse of these materials as inputs, creating the Reverse Logistics as a research area. There are justifications, economic and political, which highlight the need for investment in this area of research [20,21].

It is noted that the processing of waste materials and end-of-life products, rather than using virgin raw materials, saves money, since less virgin raw material and less final disposal are used [22].

The literature on the analysis of Reverse Logistics focuses primarily on product recovery systems at the end of its useful life. Only a few previous works, such as Mondschein and Schilkrut [23], addressed the process of recovering waste/by-product in exchange networks between industries that share a considerable amount of waste.

Alternatively, Fleischmann et al. [19] conducted a study in another setting. They have used the principle that the efficient execution of closed-loop supply chains requires the creation of appropriate logistics structures for the flows derived from used and recovered products. They have considered a logistics network project in the context of Reverse Logistics. Presented a generic model of installation and discussed differences between traditional logistics such as steel, civil construction waste, electrical and electronics and carpet recycling. Moreover, they have used the model developed by them to analyze the impact of the return of the product flowing in logistics networks. It was shown that the influence of product recovery is very dependent on the context. While in many cases the product recovery can be efficiently integrated in the existing logistics structures, other examples require a more comprehensive approach to redesign a logistics network of companies in an integral way.

As evidenced in the previous sections, the corporate practice focused on sustainability can be inspired by production cycles that reduce the waste materials to the maximum. Although the SWNP and other regulatory instruments generically indicate the stimulus to the incorporation of non-virgin raw materials in the production process of the EEE, no concrete step in this direction has yet been found. It is essential to evaluate the problems derived from electrical and 
electronic wastes, from its process of industrial production to its reuse. The complex nature of the productive chain of electrical and electronic products indicates the interwoven network of inter-relationships of the industrial system involved in it, because it depends on the integration between various industries (plastics and rubber; mining and metallurgy; machinery; pulp and paper - packaging; chemical industry; glass; basic electrical materials; electronic - semiconductors, boards, circuits, other - ; software; and mechanical components). Given this situation, it is important to structure a management model for the reuse of industrial waste formed in the entire production cycle of EEE, based on the creation of a network - 5Rs Network - that allows to Reduce, Redesign, Recycle, Reuse and Repurpose the industrial waste generated in the country [16].

The conceptual map in Figure 1 shows the systemic view of Reverse Logistics of electrical and electronic waste.

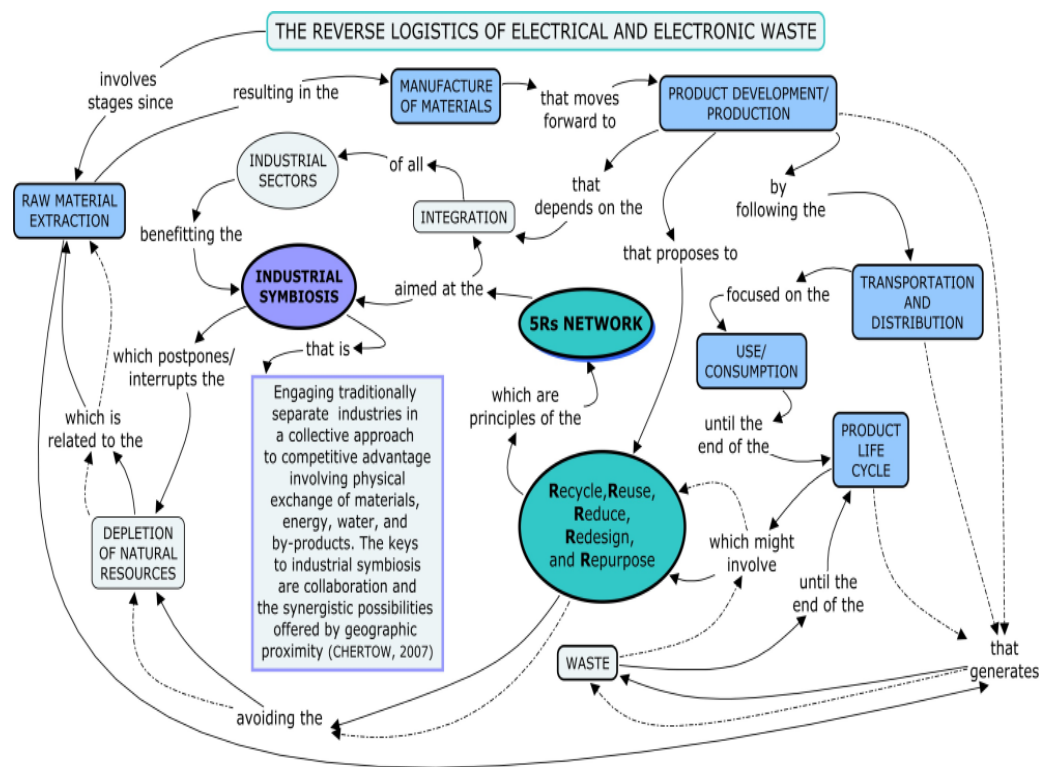

Figure 1: $\quad$ Systemic view of the Reverse Logistics of waste.

\section{The Reverse Logistics and the boundaries of companies - a unique opportunity}

The Reverse Logistics, characterized here by a systemic view that involves leveraging the opportunity to reframe the whole production chain of the electrical and electronics industry, is configured as an opportunity for new businesses development.

Companies can obtain the revenues derived from the conquest of markets by expanding its boundaries. The four main boundaries are: SCALE, SCOPE, 
EXTENTION and SPEED. Companies change their boundaries over time. For innovation, it is important to know the geography of the company's boundaries!

As the SCALE is associated with the production capacity - usually measured in terms of output per day or per year and characterized by the horizontal consolidation and growth of the company - the increased production and consumption of electrical and electronic products alone represents a real possibility of establishing a myriad of new business upstream and downstream the availability of consumer products. Whether considering the production of metals - widely used in the manufacture of parts, spare parts and components (PSP\&C) of all kinds - from mining activities at the beginning of the chain, or considering the recovery of these metals from these same PSP\&Cs on the products "discarded" by the yesterday's user, a set of demands for solutions that require SCALE would be created in order to configure them as profitable, associated with the principles of sustainability.

The range of products produced by the company is associated with the SCOPE, characterized by the lateral consolidation and diversification of the company. If every company that produces those same PSP\&Cs, associated or not with those that incorporate them in their products, gives rise to a number of startups or spin-offs related to recycling, repurposing or reusing components that integrate PSP\&Cs, a consistent perspective of generating employment and income at the national level is created.

The EXTENTION refers to the number of vertical stages of production, distribution and marketing that are undertaken by the company. This boundary is associated with the production sequence, vertical consolidation and vertical integration. An extensive look at all stages of the PSP\&Cs production processes opens huge perspectives for the innovative entrepreneurship, reaching from the processing of ores, including their materials and equipment, to the system of its post-consumer collection.

The most riveting frontier - SPEED - related to the pace of innovation, dynamic consolidation and accelerated innovation, is perfectly aligned to the Reverse Logistics in the moment that induces, in practice, a permanent set of actions that are meant to challenge conventional knowledge with the objective of creating for the unknown.

\section{Conclusion}

With the implementation of the SWNP, the 5Rs Network is now an imminent operational model of sustainable development for the repurpose of industrial waste, particularly in the electronics sector. It is important to identify that, because of the multi, trans- and interdisciplinarity, typical of the WEEE, the association between the SWNP and the 5Rs Network will reframe the Reverse Logistics of this waste. The benefit caused by the emergence of new products and businesses that will reach the regional and global market by having wide sustainable application in the global scene will be immediate.

Recognizing that it is extremely difficult for many companies to keep moving when everything seems to work well, treating Reverse Logistics in a systemic 
manner, allied with the aspects that favor the expansion of the companies' boundaries, will finally aggregate value to the national product, favoring the regional development. Involving the generation of employment and income to sustainable development - this is the way.

\section{References}

[1] Nikolopoulou, A. \& Ierapetritou, M.G. Optimal design of sustainable chemical processes and supply chains: A review. Computer and Chemical Engineering, 44, pp. 94-103, 2012.

[2] Fonseca, M. V. A. Rede 5Rs: uma inovação de contexto no desenvolvimento de produtos e serviços a partir de rejeitos industriais no Brasil. Proc. of the Seminário Nacional sobre Reuso/Reciclagem de Resíduos Sólidos Industriais, São Paulo: Secretaria de Estado de Meio Ambiente de SP/ Cetesp, 2000 (in Portuguese).

[3] Srivastava, S.K. Green supply-chain management: A state-of-the-art literature review. International Journal of Management Reviews, 9 (1), pp. 53-80, 2007.

[4] Zhu, Q. \& Cote, R.P. Integrating green supply chain management into an embryonic eco-industrial development: a case study of the Guitang Group. Journal of Cleaner Production, 12, pp. 1025-1035, 2004.

[5] Barbosa-Póvoa, A.P. Progresses and challenges in process industry supply chains optimization. Current Opinion in Chemical Engineering, (1), pp. 446-453, 2012.

[6] Brazil. Law 12.305, dated August 2, 2010. Institutes The Solid Waste National Policy. Official Gazette [of] the Federative Republic of Brazil. Brasilia, DF 02 August 2010. Available at: www.planalto.gov.br/ ccivil_03/_ato2007-2010/2010/lei/112305 (Accessed on October 20, 2013) (in Portuguese).

[7] Linton, J.D., Klassen, R. \& Jayaraman, V. Sustainable supply chains: An introduction. Journal of Operations Management, 2007. Available at: www.sciencedirect.com.

[8] Brazil. Decree No. 7,404, dated December 23, 2010. Regulate The Solid Waste National Policy. Official Gazette [of] the Federative Republic of Brazil. Brasilia, DF 23 December 2010. Available at:http:/www.planalto .gov.br/ccivil_03/_ato2007/2010/2010/Decreto/D7404.htm (Accessed on October 20, 2013) (in Portuguese).

[9] http://www.conferenciameioambiente.gov.br/wp.content/uploads/2013/02/ RESULTADO-FINAL-4CNMA1.pdf (Accessed on December 15, 2013) (in Portuguese).

[10] SINIR, http://www.sinir.gov.br/web/guest/logistica-reversa (Accessed on December 15, 2013) (in Portuguese)

[11] ABINEE - Associação Brasileira da Indústria Elétrica e Eletrônica (Brazilian Electrical and Electronic Producers Association), 2013. Desempenho Setorial (Sector Performance). São Paulo, Brasil. Available at: www.abinee.org.br (in Portuguese). 
[12] Araújo, M.G., Magrini, A., Mahler, C.F. \& Bilitewski, B. A model for estimation of potential generation of waste electrical and electronic equipment in Brazil. Waste Management, (32), pp. 335-342, 2012.

[13] Araripe, G.P.F. Proposed communication model for a college environment of the XXI Century. 2005. 227 pages. Thesis (Master of Science in Production Engineering) - Alberto Luiz Coimbra Institute for Graduate Studies and Research in Engineering, Federal University of Rio de Janeiro, Rio de Janeiro, Brazil, 2005, (in Portuguese).

[14] Frosch, R.A. \& Gallopoulos, N.E. Strategies for Manufacturing - Waste from one industrial process can serve as the raw materials for another, thereby reducing the impact of industry on the environment. Scientific American, 261 (3), pp.144-152, 1989.

[15] World Business Council for Sustainable Development (WBCSD).Available at: http://www.wbcsd.org/home.aspx. Accessed on October 10, 2013.

[16] Campos, T.R.T \& Fonseca, M.V.A. Rede 5Rs: a base estratégica para a operacionalização da SWNP, no âmbito industrial (5Rs network: the strategic basis for the operationalization of SWNP, in the industrial sector). Proc. of the XXXII Encontro Nacional de Engenharia de Produção /ENEGEP (National Meeting of Production Engineering). Bento Gonçalves (RS), 2012. (in Portuguese).

[17] Chertow, M.R., "Uncovering" Industrial Symbiosis. Journal of Industrial Ecology, 11(1), pp. 11-30, 2007.

[18] Ehrenfeld, J. \& Gertler, N. Industrial Ecology in Practice. The Evolution of Interdependence at Kalundborg. Journal of Industrial Ecology, 1(1), pp. 67-79, 1997.

[19] Fleischmann, M., Bloemhof-Ruwaard, J.M., Dekker, R., Van der Laan, E., Van Nunen, J.A.EE. \& Van Wassenhove, L.N. Quantitative models for reverse logistics: a review. European Journal of Operational Research, 103, pp.1-17, 1997.

[20] Corbett, C.J. \& Kleindorfer, P.R. Environmental Management and Operations Management: Introduction to part 1 (Manufacturing and Ecologistics). Production and Operations Management, 10 (2), pp.107-111, 2001.

[21] Corbett, C.J. \& Kleindorfer, P.R. Environmental Management and Operations Management: Introduction to part 2 (Integrating Operations and Environmental Management Systems). Production and Operations Management, 10 (3), pp.225-227, 2001.

[22] Pourmohammadi, H., Rahimi, M. \& Dessouky, M. Sustainable Reverse Logistics for Distribution of Industrial Waste/Byproducts: A joint optimization of operation and environmental costs. Supply Chain Forum, An International Journal, 9 (1), pp. 2-17, 2008.

[23] Mondschein S.V. \& Schilkrut A. Optimal Investment Policies for Pollution Control in the Copper Industry. Interfaces, 27 (6), pp.69-87, 1997. 